\title{
ESTUDO EXPERIMENTAL SOBRE O CONGELAMENTO DO PLASMA E IMPLICAÇÕES REFERENTES À TRANSMISSÃO DA DOENÇA DE CHAGAS EM SERVIÇOS DE HEMOTERAPIA *
}

\author{
Vicente Amato Neto **, Ricardo Ribeiro dos Santos *** e Ismael Gióia ***
}

\begin{abstract}
Plasmas de individuos normais e de pacientes com a forma crônica da doença de Chagas foram, intencionalmente, contaminados com cepa muito virulenta do Trypanosoma cruzi $e$, a seguir, congelados a $-20^{\circ} \mathrm{C}$, durante seis e 24 horas, como também no decurso de três ,sete, 14 e 21 dias. Depois de descongelamento em temperatura ambiente, ocorreram exame microscópico a fresco em contraste de fase, cultivo em meio de Warren e inoculação em camundongos, com subseaüente anälise histopatológica do coração. Através dessas pesquisas, a sobrevivéncia do flagelado ficou avaliada, tendo sido verificado que o congelamento por três e 24 horas não impediu a persistência do parasita infetante. Salientaram os Autores que a investigação que levaram a efeito procurou contribuir no sentido de prestar orientação quanto às transfusões de plasmas, em Serviços de Hemoterapia, convindo frisar que no Brasil elas são efetuadas com razoável freqüênêcia, mediante utilização de doadores acometidos pela doença de chagas e com a convicção de que baixas temperaturas promovem segura esterilização.
\end{abstract}

\section{INTRODUÇÃO}

A importância da transmissão da doença de Chagas através de transfusão de sangue está atualmente confirmada de forma cabal. As elevadas percentagens de indivíduos com infeç̧ão crônica pelo Trypanosoma cruzi que são doadores de sangue e, também, os reiterados relatos de contaminações devidas a esse protozoário, atestam o significado da hemoterapia na disseminação do processo mórbido em apreço (1)

Com finalidade profilática, a adição de cristal violeta ou de violeta de genciana aos sangues a serem administracios, quando houve confirmação da presença da parasitose e em situações que não permitem conveniente triagem por meio de adequados e eficientes recursos laboratoriais, é medida dotada de comprovado valor $(2,3)$; no entanto, essa providência não é costumeiramente adotada por responsáveis de Bancos de Sangue e, com base em argumentos inaceitáveis, ocorrem tentativas no sentido de explicar essa imprópria forma ce agir.

Tomamos conhecimento, recentemente, de que plasmas de pessoas com doença de Chagas ou não submetidas à necessária

* Trabalho da Discipina de Doenças Transmis siveis, do Departamento de Clínica Médica, da Faculdade de Ciências Médicas, da Universtdade Estadual de Campinas.

* Professor Titular do Departamento de Clínica Médica, responsável pela Disctplina de Doenças Transmissiveis.

** Assistente da Disciplina de Doenças Transmissíteis.

*** Biologista do Departamento de Parasitologia, do Instituto de Biologia, da Uitiversidade Estadual de Campinas.

Recebido para publicação em 3-4-75. 
seleção, são transfundidos, após congelamento, com a convicção de que baixas temperaturas têm a capacidade cie impedir posterior participação infetante do Trypanosoma cruzi. Como esse assunto ainda não mereceu abordagem específica, por intermédio de indispensável investigação experimental, resolvemcs efetuar pesquisa sobre ele, executando observações em camundongos e empregando cepa altamente virulenta do protozoário.

\section{MATERIAL E MÉTODOS}

No decurso da investigação, levamos em conta as etapas adiante dezcritas:

a) misturamos partes iguais de dez plasmas de indivíciuos não doentes e obtidos de sangues colhidos em solução ACD;

b) misturamos partes iguais de cinco plasmas de indivíduos com doença de Chagas e obtidos de sangues colhidos em solução ACD; a confirmação da existência da parasitose foi forneciảa pela positividade da reação de fixaçāo do complemento;

c) utilizamos formas tripomastigotas da cepa $\mathrm{Y}$ do Trypanosoma cruzi (4), procedentes do sangue circulante de camundongos infetados (Mus musculus);

d) separamos 24 * alíquotas de $2 \mathrm{ml}$ de plasmas e em cada uma colocamos $2 \times 10^{6}$ formas tripomastigotas metacíclicas do Trypanosoma cruzi;

e) congelamos, a $-20^{\circ} \mathrm{C}$, seis alíquotas da mistura de plasmas de indivíduos não doentes e outras tantas da de pessoas com doença de Chagas;

f) realizamos descongelamento, em temperatura ambiente, após seis e 24 horas e, outrossim, ciepois de três, sete, 14 e 21 dias;

g) a seguir, efetuamos exame direto de uma gota através de microscopia de contraste de fase, assim como semeamos cerca de $0,2 \mathrm{ml}$ em cinco tubos com meio de Warren e inoculamos, pela via intraperitcneal, $0,5 \mathrm{ml}$ em camundongos com $5 \mathrm{~g}$ de peso; quanto às culturas, centrifugamos decorridos dez dias e pesquisamos o protozoário da maneira já referida e, a propó- sito dos animais, analisamos a parasitemia no oitavo e décimo-quinto dias posteriores à inoculação, sendo que nesta última ocasião sacrificamo-los, para empreender análise histopatológica do coração, mediante coloração pela hematcxilina-eosina.

\section{RESULTADOS}

As nossas verificações estão expostas nos Quadros I e II. Apenas convém acrescentar que nos fragmentos do coração correspondentes a congelamento dos plasmas, durante seis e 24 horas era perceptível infiltrado inflamatório linfomononuclear, de maior intensidade naqueles concernentes ao periodo menos duradouro.

\section{DISCUSSÃO}

Os fatos que apuramos permitem, acrecitamos, consignar os comentários adiante especificados.

1) Ficou evidente, pelo menos de acordo com a forma adotada para proceder à investigação, que não é permissível transfundir plasmas de doares acometidos de doença de Chagas, mesmo posteriormente a congelamento, a $-20^{\circ} \mathrm{C}$, no decurso de 24 horas.

2) Não documentamos persistência de Trypanosoma cruzi viável e infetante quando o tempo de congelação foi de três ou mais dias e, a propósito, salientamos que colocamos, nos materiais sob experimentação, quantidade apreciável de parasitas, habitualmente não detectada no sangue, quando encontra-se vigente a etapa crônica da parasitose.

3) A participação de anticorpos específicos não influiu categoricamente sobre os resultados que registramos, conformecomprovam os dados anotados nos Quadros I e II.

4) É lógico que a pesquisa que empreendemos fornece orientação de ordem prática a respeito de situações congêneres às nela estabelecidas, não podendo mereces generalização e justificar aplicaçõe $e_{S}$ ligadas à prevalência de condições diversas das levadas em conta.

\footnotetext{
* 12 ficaram em geladeira, a $4^{\circ} \mathrm{C}$, durante três horas antes do congelamento; como obtivemos com el resultados iguais aos descritos no texto, tendo havido idêntica experimentação, nāo descrevemas que com esses materiais sucedeu.
} 
QUADRO I - Estudo acerca da sobrevida do Trypanosoma cruzi em plasmas congelados durante diferentes períodos: resultados correspondentes a materiais obtidos de individuos não doentes e contaminados com cepa virulenta do flagelado.

\begin{tabular}{|c|c|c|c|c|c|}
\hline \multirow{2}{*}{$\begin{array}{l}\text { Congela- } \\
\text { mento a } \\
-20^{\circ} \mathrm{C}\end{array}$} & \multirow{2}{*}{$\begin{array}{l}\text { Exame } \\
\text { direto }\end{array}$} & \multirow{2}{*}{ Cultura } & \multicolumn{2}{|c|}{ Inoculação * } & \multirow{2}{*}{$\begin{array}{c}\text { "Ninhos" } \\
\text { de formas } \\
\text { amastigotas } \\
\text { ao exame } \\
\text { histopatológico } \\
\text { do coração }\end{array}$} \\
\hline & & & $8 .^{\circ}$ dia & $15 .^{\circ} \mathrm{dia}$ & \\
\hline $6 \mathrm{~h}$ & $1100 / \mathrm{mm}^{3}$ & $\mathbf{P}$ & $1200 / \mathrm{mm}^{3}$ & $3200 / \mathrm{mm}^{3}$ & PR \\
\hline $24 \mathrm{~h}$ & $150 / \mathrm{mm}^{3}$ & $\mathbf{P}$ & $150 / \mathrm{mm}^{3}$ & $350 / \mathrm{mm}^{3}$ & PR \\
\hline $3 d$ & $\mathrm{~N}$ & $\mathrm{~N}$ & $\mathbf{N}$ & $\mathrm{N}$ & A \\
\hline $7 \mathrm{~d}$ & $N$ & $\mathrm{~N}$ & $\mathrm{~N}$ & $\mathrm{~N}$ & A \\
\hline $14 \mathrm{~d}$ & $\mathrm{~N}$ & $\mathrm{~N}$ & $\mathrm{~N}$ & $\mathrm{~N}$ & A \\
\hline $21 d$ & $\mathrm{~N}$ & $\mathrm{~N}$ & $\mathbf{N}$ & $\mathbf{N}$ & A \\
\hline
\end{tabular}

h: horas; d: dias; P: positiva; PR: presentes; $\mathrm{N}$ : negativo ou negativa; A: ausentes; os números correspondem a tripasonossomas.

QUADRO II - Estudo acerca da sobrevida do Trypanosoma cruzi em plasmas congelados durante diferentes periodos: resultados correspondentes a materiais obtidos de indivíduos com doença de Chagas e contaminados com cepa virulenta do flagelado.

\begin{tabular}{|c|c|c|c|c|c|}
\hline \multirow{2}{*}{$\begin{array}{l}\text { Congela- } \\
\text { mento a } \\
-20{ }^{\circ} \mathrm{C}\end{array}$} & \multirow{2}{*}{$\begin{array}{c}\text { Exame } \\
\text { direto }\end{array}$} & \multirow{2}{*}{ Cultura } & \multicolumn{2}{|c|}{ Inoculação * } & \multirow{2}{*}{$\begin{array}{c}\text { "Ninhos" } \\
\text { de formas } \\
\text { amastigotas } \\
\text { ao exame } \\
\text { histopatológico } \\
\text { do coração }\end{array}$} \\
\hline & & & $8 .^{\circ}$ dìa & $15 .^{\circ} \mathrm{dia}$ & \\
\hline $6 \mathrm{~h}$ & $950 / \mathrm{mm}^{3}$ & $P$ & $1700 / \mathrm{mm}^{3}$ & $5100 / \mathrm{mm}^{3}$ & PR \\
\hline $24 \mathrm{~h}$ & $25 / \mathrm{mm}^{3}$ & $\mathbf{P}$ & $\mathbf{N}$ & $250 / \mathrm{mm}^{3}$ & $A$ \\
\hline $3 \mathrm{~d}$ & $\mathrm{~N}$ & $\mathbf{N}$ & $\mathbf{N}$ & $\mathbf{N}$ & A \\
\hline $7 d$ & $\mathrm{~N}$ & $\mathbf{N}$ & $\mathrm{N}$ & $\mathrm{N}$ & A \\
\hline $14 d$ & $\mathrm{~N}$ & $\mathrm{~N}$ & $N$ & $\mathbf{N}$ & A \\
\hline $21 \mathrm{~d}$ & $\mathrm{~N}$ & $\mathbf{N}$ & $\mathrm{N}$ & $\mathbf{N}$ & A \\
\hline
\end{tabular}

h: horas; d: dias; P: positiva; PR: presentes: $\mathrm{N}$ : negativo o'l negativa; A: ausentes; as números correspondem a tripasonossomas. 


\section{$S U M M A R$}

The plasmas of normal subjets and of patients with chronic Chagas' disease were intentionally contaminated with a very virulent strain of Trypanosoma cruzi. The specimens were frozen to $-20^{\circ} \mathrm{C}$ during three and twenty-four hours and for three, seven, fourteen and twenty-one days. After the aliquots were warmed to ambient temperature, they were examined as a fresh smear under contrast phase micrascopy, cultivated in Warren's medium and inoculated in mice for subsequent histopathological examination of the heart. The results indicated that freezing during three and twenty-four hours did not prevent survival of the infecting parasite. The purpose of the study was to contribute to the orientation of plasma transfusion in blood transfusion centers. Since plasma transfusion is commonplace in this country, many times collected from infected donors with Chagas disease, we wish to decry the notion that low temperatures securely promote sterilization.

\section{REFERENCIAS BIBLIOGRÁFICAS}

1. CERISOLA, J.A., RABINOVICH, A., ALVAREZ, M., DI CORLETO, C.A. \& FRUNEDA, J. - Enfermedad de Chagas y la transfusion de sangre. Bol. $O f$. Sanit. Panamer., 53: 203-221, 1972.

2. KLOETZEL, J. - Estudo comparativo da ação tripanossomicicia "in vitro" da violeta de genciana e do cristal violeta. Primeiros ensaios com o emprego do verde de metila. Rev. Inst. Med. Trop. São Paulo, 3: 254-260, 1961.

3. NUSSENZWEIG, V., SONNTAG, R., BIANCAIANA, A., PEDREIRA' DE
FREITAS, J.L., AMATO NETO, V. \& KLOETZEL, J. - Ação de corantes tri-fenil-metânicos sobre o Trypanosoma cruzi "in vitro". Emprego da violeta de genciana na profilaxia da transmissão da moléstia de Chagas por transfusão de sangue. Hospital (Rio), 44: 731-744, 1853 .

4. PERETRA DA SLLVA, L.H. \& NUSSENZWEIG, V. - Sobre uma cepa de Trypanosoma cruzi altamente virulenta para o camundongo branco. Folia Clin. Biol. (São Paulo), 20: 191-208, 1953. 